\title{
Identifying and characterizing hepatitis $C$ virus hotspots in Massachusetts: a spatial epidemiological approach
}

Thomas J. Stopka ${ }^{1 *}$ D, Michael A. Goulart ${ }^{1}$, David J. Meyers ${ }^{1,2}$, Marga Hutcheson ${ }^{1}$, Kerri Barton ${ }^{3}$, Shauna Onofrey ${ }^{3}$, Daniel Church" ${ }^{3}$ Ashley Donahue and Kenneth K. H. Chui ${ }^{1}$

\begin{abstract}
Background: Hepatitis $\mathrm{C}$ virus ( $\mathrm{HCV}$ ) infections have increased during the past decade but little is known about geographic clustering patterns.

Methods: We used a unique analytical approach, combining geographic information systems (GIS), spatial epidemiology, and statistical modeling to identify and characterize HCV hotspots, statistically significant clusters of census tracts with elevated HCV counts and rates. We compiled sociodemographic and HCV surveillance data ( $n=99,780$ cases) for Massachusetts census tracts $(n=1464)$ from 2002 to 2013 . We used a five-step spatial epidemiological approach, calculating incremental spatial autocorrelations and Getis-Ord Gi* statistics to identify clusters. We conducted logistic regression analyses to determine factors associated with the HCV hotspots.

Results: We identified nine HCV clusters, with the largest in Boston, New Bedford/Fall River, Worcester, and Springfield $(p<0.05)$. In multivariable analyses, we found that HCV hotspots were independently and positively associated with the percent of the population that was Hispanic (adjusted odds ratio [AOR]: 1.07; 95\% confidence interval [CI]: 1.04, 1.09) and the percent of households receiving food stamps (AOR: 1.83; 95\% Cl: 1.22, 2.74). HCV hotspots were independently and negatively associated with the percent of the population that were high school graduates or higher (AOR: $0.91 ; 95 \% \mathrm{Cl}: 0.89,0.93$ ) and the percent of the population in the "other" race/ethnicity category (AOR: 0.88; 95\% Cl: 0.85, 0.91).

Conclusion: We identified locations where HCV clusters were a concern, and where enhanced HCV prevention, treatment, and care can help combat the HCV epidemic in Massachusetts. GIS, spatial epidemiological and statistical analyses provided a rigorous approach to identify hotspot clusters of disease, which can inform public health policy and intervention targeting. Further studies that incorporate spatiotemporal cluster analyses, Bayesian spatial and geostatistical models, spatially weighted regression analyses, and assessment of associations between HCV clustering and the built environment are needed to expand upon our combined spatial epidemiological and statistical methods.
\end{abstract}

Keywords: Getis-Ord Gi*, Spatial clusters, GIS, Surveillance, Infectious diseases

\footnotetext{
* Correspondence: thomas.stopka@tufts.edu

${ }^{1}$ Department of Public Health and Community Medicine, Tufts University

School of Medicine, 136 Harrison Avenue, Boston, MA 02111, USA

Full list of author information is available at the end of the article
} 


\section{Background}

Approximately 71.1 million people are estimated to be currently infected with the hepatitis $\mathrm{C}$ virus (HCV) worldwide [1]. The number of people infected in the U.S. alone is estimated to be more than three million, of whom 75\% were born between 1945 and 1965 [2]. Ageadjusted HCV mortality rates have increased steadily in recent decades [3], and notable increases in HCV cases have been reported in many states across the U.S. [4] At least $60 \%$ of prevalent $\mathrm{HCV}$ infections and nearly all incident $\mathrm{HCV}$ infections are attributed to injection drug use (IDU) [5-8], with an increasing burden among young people who inject drugs (PWID) [3-6] in nonurban, white communities [4].

Recent HCV surveillance data in Massachusetts (MA) identified a new HCV epidemic pattern characterized by a bimodal age distribution, with the expected peak among 45-65 year olds and an emerging peak among 15-30 year olds $[9,10]$. There was a $78 \%$ increase in HCV cases among adolescents and young adults (1524 years) in MA between 2002 and 2009, and an increase of $137 \%$ in the 15-29-year-old population between 2002 and 2013 [9, 10]. HCV surveillance is greatly underfunded across the United States [11], and limited spatial epidemiological and geostatistical analysis of surveillance data has been performed to date.

Innovative analytical approaches can foster a better understanding of disease transmission and improved preparation for targeted responses. Studies have demonstrated that GIS-guided approaches to disease screenings have a higher yield than traditional screening methods [12-15]. Information on where infections cluster may enhance disease prevention, treatment, and care. For example, in Connecticut, researchers used a mix of statistical and geographic information system (GIS) methods to identify unique spatial distributions and characteristics for HCV and related infections [16]. Along the U.S.-Mexico border, spatial epidemiological methods were used to identify HIV clusters, and to determine that most seroconversions were occurring in a 2.5 block radius in the red light district of Tijuana [17]. In MA, we identified HCV and HIV all-cause mortality hotspots from 2002 to 2012 [18]. However, GIS and spatial analyses to date have been relatively simplistic in their approach and new, more methodologically rigorous spatial cluster analyses are needed to pinpoint locations (i.e., "hotspots") with highest needs for intervention. The objectives of our study were to: (1) identify HCV clusters in MA using GIS and spatial epidemiology, and (2) to characterize the HCV clusters through statistical modeling.

\section{Methods}

We defined a hotspot as a location with a statistically significant cluster of census tracts with higher counts and rates of $\mathrm{HCV}$ than the average count/rate for all census tracts in MA [18].

\section{Data and measures}

We obtained a partially de-identified, limited HCV surveillance dataset from the Massachusetts Department of Public Health (MDPH) that included 99,780 records of people with evidence of past or present infection with HCV reported from 2002 to 2013. All laboratory test results indicative of $\mathrm{HCV}$ infection are reportable to $\mathrm{MDPH}$. Most of these reports are received via electronic laboratory reporting into the MA Virtual Epidemiologic Network (MAVEN), MDPH's secure, web-based, electronic surveillance system [19]. The data are comprised of all newly reported probable and confirmed cases of $\mathrm{HCV}$ during the time period and offer the most complete window to prevalent $\mathrm{HCV}$ infection patterns available. CDC case definitions were employed. A probable HCV case was a case that did not meet the case definition for acute $\mathrm{HCV}$, was anti-HCV positive (repeat reactive) by enzyme immunoassays (EIA), and had alanine aminotransferase (ALT or SGPT) values above the upper limit of normal, but the anti-HCV EIA result had not been verified by an additional more specific assay or the signal to cut-off ratio was unknown. A confirmed HCV case was defined as a case that was laboratory confirmed and did not meet the case definition for acute $\mathrm{HCV}$. Reported variables include year of report, sex, mode of transmission (IDU vs. non-IDU), race/ethnicity, and address. Address information was missing for 15,541 records. Our final analytical dataset included 84,255 HCV cases.

\section{Demographic and risk variables and rate computation}

We obtained population denominators and sociodemographic data on the census tract level from U.S. Census Bureau's American Community Survey (ACS) [20]. As of the 2010 Census, there were 1478 census tracts in MA. Using GIS and ACS data, we calculated HCV counts and rates of infection per 100,000 persons at the census tract level. Independent variables were selected based on prior research and the scientific literature. Continuous explanatory variables included race/ethnicity, age, education level, households receiving food stamps, and housing status. We used rank order histograms to determine median or tertile cut-offs based on the skewness of the data. We categorized continuous variables using the median as a cut point for non-linear increases or decreases that were monotonic. We categorized continuous variables by tertile for non-linear trends that demonstrated a U-shape or inverted U-shape. Explanatory variables for total population, and household income were dichotomized at the median, and the continuous variables for households living in poverty, 
households with one worker, and households with two or more workers were categorized by tertiles. Census tracts with a total population of $<1$ were excluded from all analyses, resulting in omission of 14 tracts $(n=1464)$.

\section{Other potentially associated geographic features}

Addresses for health facilities, including HIV testing sites and syringe exchanges, were obtained from MDPH. Addresses for pharmacies and prisons were obtained from the MA State Board of Pharmacy and MassGIS, respectively. Adult bookstores and gay bars were obtained through publicly available webpages and Internet directories targeting this community. All health resources and other venues that could be associated with hotspots, based on the literature and prior research, were aggregated to the census tract level.

\section{Spatial analyses}

We used a combination of GIS, spatial epidemiological, and statistical analyses to: (1) identify the geolocation of statistically significant hotspot clusters of $\mathrm{HCV}$ cases, and (2) determine community-level factors (i.e., social determinants) associated with these clusters.

\section{Data cleaning}

We standardized address fields in SAS (v9.4, Cary, NC). The process involved parsing the addresses into different segments, unifying acronyms (e.g., changing "Str," "Street," "street," and "st" into "St"), removing superfluous characters (e.g., the "\#" sign), and correcting mismatched ZIP codes. The resultant segments were then rearranged into three variables: street address, town, and ZIP code, which were used for geocoding.

\section{Geocoding}

Geocoding is the process of obtaining longitude and latitude coordinates for an address or the geocentroid of a polygon (e.g., census tract) [21]. We geocoded the cleaned HCV cases in ArcGIS 10.2.2, using an address locator created from the U.S. Census Bureau's 2014 Topologically Integrated Geographic Encoding and Referencing (TIGER) Line Shapefiles. We ran addresses that did not initially match through Google Earth's desktop geocoder, which uses multiple algorithms to improve geographic match rates. Throughout our extensive cleaning processes, 66,023 observations were successfully matched in ArcMap with 16,133 more matching in Google Earth. This resulted in a total of 82,211 matched addresses for an overall match rate of $82.3 \%(82,211 /$ 99,780). For our analytical dataset, which included complete addresses for all HCV cases $(n=84,255)$, we achieved a match rate of $97.6 \%(82,211 / 84,255)$. These match rates are similar to those in other studies in the literature [22].

\section{Descriptive mapping and cluster analyses}

We conducted GIS and spatial epidemiological analyses to determine the burden of disease across MA. First, we created thematic GIS maps to determine the initial spatial distribution of $\mathrm{HCV}$ cases and rates. Data were aggregated at the census tract level to protect the confidentiality of people living with $\mathrm{HCV}$ while maintaining the optimal spatial resolution. Next, we used Kernel Density Estimation (KDE) to construct a smoothed surface of $\mathrm{HCV}$ cases across MA. KDE analyses incorporate the number and proximity of cases within defined geographic areas [23]. The final results from this method can be interpreted as the density of $\mathrm{HCV}$ cases per square mile.

We then used tests of spatial autocorrelation and hotspot analyses to identify the location of clusters of $\mathrm{HCV}$ case counts and rates per 100,000 population. Using ArcGIS 10.2.2 (ESRI, Redlands, CA), we first used incremental spatial autocorrelation at 30 different distances to determine the distance at which clustering was most intense (i.e., had the highest z-score) for each specified outcome [24]. The spatial scale (i.e., the distance) obtained from these results was then entered as a parameter in the subsequent Getis-Ord $\mathrm{Gi}^{*}$ hotspot analyses. These analyses allowed us to identify the location of statistically significant clusters of census tracts with higher (or lower) values for $\mathrm{HCV}$ cases and infection rates [25]. Next, we conducted spatiotemporal cluster analysis (SaTScan v9.3) to determine temporal clustering patterns in micro-communities across specific years using a space-time cluster scanning statistic [26]. This model can be run at different scanning window sizes which limit the potential size of a discovered cluster. We ran this model at a $25 \%$ scanning window which we selected a priori to represent a balance of granular level cluster detection without exposing the analysis to excessive noise. Finally, we compared results across our four geostatistical analyses to observe consistencies in conclusions. Our spatial analytical methods are described in further detail elsewhere [18, 27].

\section{Statistical analyses}

After identifying $\mathrm{HCV}$ hotspot clusters, we calculated descriptive statistics (Chi-squared tests and two sample t-tests) for HCV cases with and without addresses and for matched and unmatched addresses in the geocoding process to determine whether there were differences in the $\mathrm{HCV}$ cases by geocode status. Next, we conducted logistic regression analyses to determine the factors associated with HCV hotspots.

Statistical analysis was performed in two stages. First, to obtain the unadjusted relationship we regressed hotspot status on each of the independent variables. Variables with an overall $p$-value $<0.25$ were retained for the 
multivariable models. For multiple logistic regression analyses, significant collinearities (variance inflation factor $>6$ ) were observed between "\% of owner-occupied housing units" and "\% of renter-occupied housing units"; between "\% African American" and "\% White; and "\% Asian" and "\% other race/ethnicity"; and between "\% male" and "\% female". To alleviate the inflation in variance caused by the aforementioned collinearities, and based on strength of association with the outcome, we removed percentages of female, total population of owner-occupied housing, White, and Asian from the adjusted model. DFBeta and residual analyses revealed no influential points or potential outliers. A Hosmer and Lemeshow Goodness-of-Fit test was conducted with $p=0.46$, indicating the model fit the data well. All statistical analyses were performed using SAS v9.4. Statistical significance was determined a priori at $p<0.05$.

\section{Results}

\section{Spatial analysis results}

Through initial descriptive GIS maps, we found that reported $\mathrm{HCV}$ infection case counts and rates were prominent across many MA municipalities between 2002 and 2013 (Fig. 1a, b). Through KDE, we identified areas with the highest densities of $\mathrm{HCV}$ cases per square mile. The Greater Boston area, New Bedford, Fall River, Lawrence, Lowell, Worcester, Springfield, Holyoke, and Fitchburg had densities of 477 to $1070 \mathrm{HCV}$ cases per square mile (Fig. 1c). We identified nine statistically significant hotspot clusters for $\mathrm{HCV}$ case counts, with the largest clusters in Boston, New Bedford/Fall River, Worcester, and Springfield $(p<0.05)$ (Fig. 1d). We found clusters for $\mathrm{HCV}$ rates per 100,000 persons in Boston, New Bedford, and Springfield (Fig. 1e). Through space-time cluster analyses, we detected similar geographic clusters, with a large coldspot in the Metro West region, and hotspots in the Greater Boston area and the South Shore of Massachusetts (Fig. 1f). We ran hotspot cluster analyses separately for HCV cases among 15-30 year olds and 45-65 year olds and no notable differences in spatial clustering patterns were detected. In Table 1 , we highlight agreement in results across our four geostatistical analytical methods, and rank areas of highest concern.

\section{Statistical results}

In Table 2, we present descriptive statistics for the characteristics of the $\mathrm{HCV}$ cases we analyzed, comparing $\mathrm{HCV}$ cases with and without addresses, and HCV cases with addresses that were successfully and unsuccessfully matched through geocoding. We noted significant differences across HCV case characteristics in both comparisons.

We present descriptive statistics for $\mathrm{HCV}$ hotspot and non-hotspot census tracts in Table 3. We noted significant differences, across race/ethnicity, gender, and socioeconomic variables. In bivariate logistic regression analyses (Table 4), total population, population density, percent of population that was Hispanic, percent high school graduates or higher, percent living in poverty, median household income, and median age were associated with $\mathrm{HCV}$ hotspots. In multivariable logistic regression analyses, we found that $\mathrm{HCV}$ hotspots were independently and positively associated with the percent of the population that was Hispanic (adjusted odds ratio [AOR]: 1.07; 95\% confidence interval $[\mathrm{CI}]: 1.04,1.09)$ and the percent of households receiving food stamps (AOR: 1.83; 95\% CI: 1.22, 2.74). $\mathrm{HCV}$ hotspots were independently and negatively associated with the percent of the population that were high school graduates or higher (AOR: 0.91; 95\% CI: 0.89, 0.93 ) and the percent of the population in the "other" race/ethnicity category (AOR: 0.88 ; 95\% CI: $0.85,0.91$ ) (Table 4).

\section{Discussion}

Our combined use of GIS, spatial epidemiological, and statistical modeling approaches allowed us to identify and characterize statistically significant geographic $\mathrm{HCV}$ hotspot clusters. We observed agreement across the different geostatistical methods we conducted, which lends support to the idea that these locations in MA present significantly greater burdens of disease. Our HCV hotspots based on HCV counts highlighted nine clusters, the largest of which included Boston, Fall River, New Bedford, Worcester, and Springfield, where the burden of disease is highest. We detected hotspots for $\mathrm{HCV}$ rates per 100,000 persons in Boston, New Bedford, and Springfield. Given that these hotspots are based on rates, controlling for population differences across census tracts in MA, they may represent locations with some of the greatest need for enhanced $\mathrm{HCV}$ prevention and treatment interventions. It is notable that each of these cities has a population with lower median age than those found across MA, and that authorized syringe exchange programs have not been available in New Bedford and Springfield, despite initiation of such programs elsewhere in MA in the 1990s, and Worcester, Lawrence and a number of additional sites in 2016.

In our multivariable analyses, we found that the percent of population that was Hispanic and the percent of households receiving food stamps were independently and positively associated with HCV hotspots, while the percent of the population that was another race/ethnicity and the percent of the population that had a high school education or higher were negatively associated with $\mathrm{HCV}$ hotspots. These associations help us to understand the underlying sociodemographic factors that are associated with $\mathrm{HCV}$ clusters. The associations 


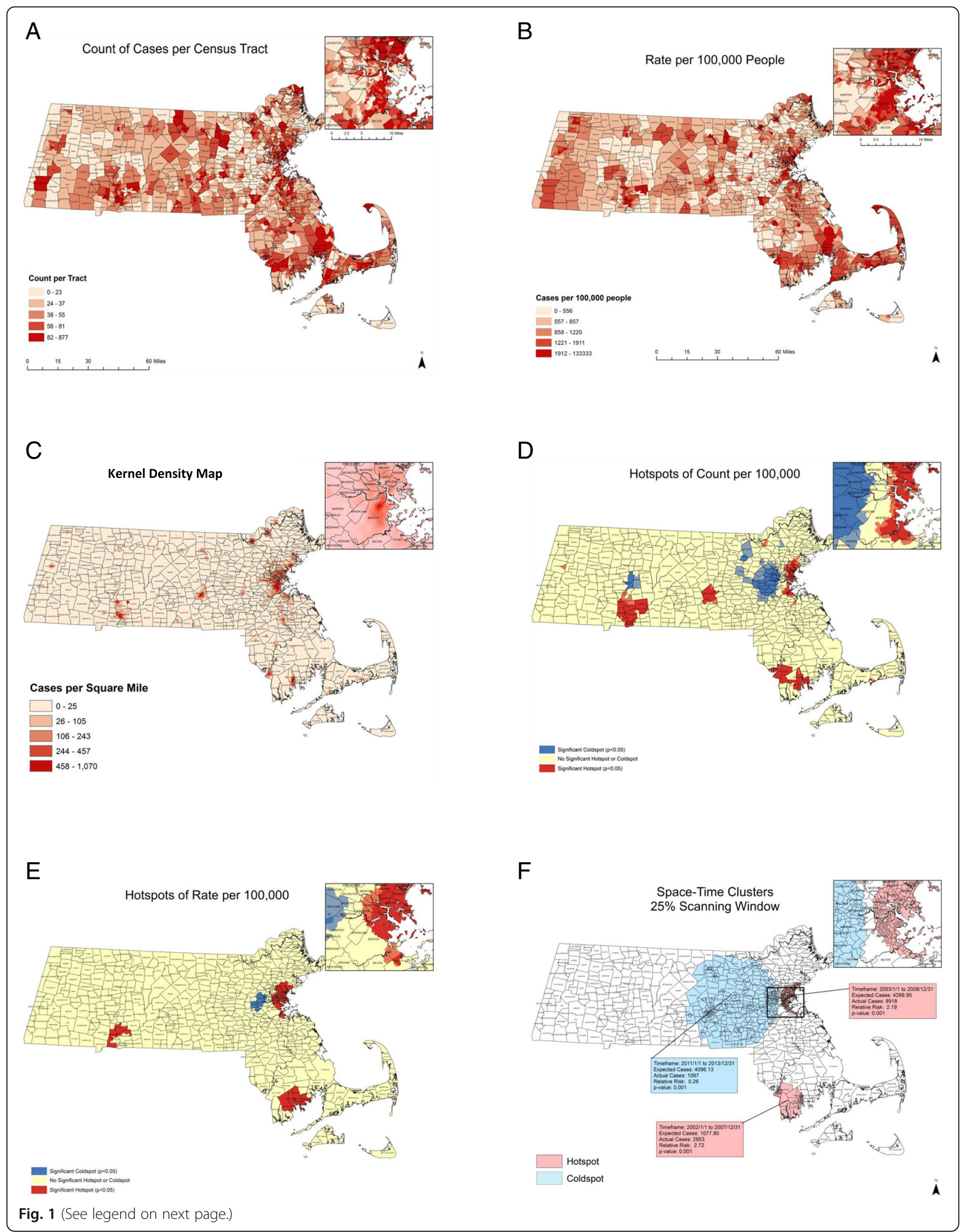


(See figure on previous page.)

Fig. 1 a HCV cases aggregated at the census tract level in Massachusetts, 2002-2013. b HCV rates per 100,000 in Massachusetts census tracts, 2002-2013. c Density of HCV cases per square mile in Massachusetts, 2002-2013. d HCV clusters in Massachusetts based on reported HCV counts aggregated at the census tract level $(n=1464)$. Census tracts with elevated numbers of HCV cases (red) represent hotspots $(p<0.05)$; census tracts with low numbers of HCV cases (blue) represent coldspots $(p<0.05)$; census tracts with average numbers of HCV cases are represented in yellow. e HCV clusters in Massachusetts based on rates per 100,000 population at the census tract level. Census tracts with elevated HCV rates (red) represent hotspots ( $p<0.05$ ); census tracts with low HCV rates (blue) represent coldspots $(p<0.05)$; census tracts with average HCV rates are represented in yellow; f Space-time clusters of HCV in Massachusetts, 2002-2013

we observed with racial/ethnic groups differ from recent findings that highlight an emerging $\mathrm{HCV}$ epidemic among non-urban, white youth and younger populations [4]. However, the associations we observed between high school education, belonging to the "other" racial/ethnic groups, and HCV hotspots echo the significant health disparities that exist among different racial/ethnic minorities, educational attainment, and income levels for HCV [28]. Since the surveillance data upon which our analyses depend cover the timeframe from 2002 to 2013, it may not be possible to discern more recent patterns in disease transmission. Confirmed and probable cases of $\mathrm{HCV}$ infection include individuals that have past exposure, but not current infection. Analysis of more recent surveillance data may begin to uncover different patterns, including the emerging epidemic among young, suburban, white communities.

Our findings may have implications for future disease transmission risks and for the future success of $\mathrm{HCV}$ treatment among PWID, for which there are many sound recommendations [29]. PWID have experienced a number of barriers along the $\mathrm{HCV}$ care cascade, which includes diagnosis of disease, linkage to care, treatment, retention, and cure. Targeting of future treatment or cure as prevention (CasP) approaches [30, 31] could benefit from spatial epidemiological analyses that identify and characterize HCV hotspot clusters. Antiviral treatment uptake among PWID has been limited by barriers at patient, provider, and structural levels [32]. With the advent of direct acting antiviral (DAA) therapy, many payers, including most state Medicaid programs, continue to require abstinence from illicit drug use and often restrict treatment by fibrosis stage [33]. These policies systematically exclude many PWID who have not yet suffered from decades of infection and present barriers to performing real-life CasP interventions in locations and populations with the highest risk of $\mathrm{HCV}$ transmission. In MA, as of August 2016, all versions of Medicaid and most private insurers approve DAAs at fibrosis stage F0 or higher and without strict sobriety criteria, facilitating PWID treatment. However, multiple barriers remain for PWID along the cascade, resulting in a very small fraction likely to reach cure [31].

Table 1 Comparison of geostatistical findings highlighting locations with high and low reported HCV infections, Massachusetts, 2002-2013

\begin{tabular}{|c|c|c|c|c|}
\hline Location & Kernel density analysis & $\begin{array}{l}\text { Getis-Ord Gl* hotspot } \\
\text { test (count) }\end{array}$ & $\begin{array}{l}\text { Getis-Ord Gl* hotspot } \\
\text { test (rate) }\end{array}$ & $\begin{array}{l}\text { Poisson space-time } \\
\text { cluster test }\end{array}$ \\
\hline Greater Boston area & Higher caseload per square mile & $\begin{array}{l}\text { Statistically significant } \\
\text { hot spot }\end{array}$ & $\begin{array}{l}\text { Statistically significant } \\
\text { hot spot }\end{array}$ & $\begin{array}{l}\text { Statistically significant } \\
\text { hot spot }\end{array}$ \\
\hline $\begin{array}{l}\text { South shore of } \\
\text { Massachusetts }\end{array}$ & Higher caseload per square mile & $\begin{array}{l}\text { Statistically significant } \\
\text { hot spot }\end{array}$ & $\begin{array}{l}\text { Statistically significant } \\
\text { hot spot }\end{array}$ & $\begin{array}{l}\text { Statistically significant } \\
\text { hot spot }\end{array}$ \\
\hline Springfield & Higher caseload per square mile & $\begin{array}{l}\text { Statistically significant } \\
\text { hot spot }\end{array}$ & $\begin{array}{l}\text { Statistically significant } \\
\text { hot spot }\end{array}$ & No significant cluster \\
\hline Worcester & Higher caseload per square mile & $\begin{array}{l}\text { Statistically significant } \\
\text { hot spot }\end{array}$ & No significant cluster & No significant cluster \\
\hline Pittsfield & Higher caseload per square mile & $\begin{array}{l}\text { Statistically significant } \\
\text { hot spot }\end{array}$ & No significant cluster & No significant cluster \\
\hline Cape Cod & Higher caseload per square mile & $\begin{array}{l}\text { Statistically significant } \\
\text { hot spot }\end{array}$ & No significant cluster & No significant cluster \\
\hline $\begin{array}{l}\text { North shore of } \\
\text { Massachusetts }\end{array}$ & Higher caseload per square mile & No significant cluster & No significant cluster & No significant cluster \\
\hline Merrimack Valley & Higher caseload per square mile & No significant cluster & No significant cluster & No significant cluster \\
\hline Metro West & $\begin{array}{l}\text { No discernable difference from } \\
\text { state average }\end{array}$ & $\begin{array}{l}\text { Statistically significant } \\
\text { cold spot }\end{array}$ & $\begin{array}{l}\text { Statistically significant } \\
\text { cold spot }\end{array}$ & $\begin{array}{l}\text { Statistically significant } \\
\text { cold spot }\end{array}$ \\
\hline
\end{tabular}


Table 2 Descriptive statistics of HCV cases by address availability and geocoding match status

\begin{tabular}{|c|c|c|c|c|c|c|}
\hline \multirow{3}{*}{ Count } & \multicolumn{3}{|l|}{ Address } & \multicolumn{3}{|l|}{ Geocoding } \\
\hline & Missing & Present & $p$-value & Unmatched & Matched & $p$-value \\
\hline & $14,980(15.01 \%)$ & 84,800 (84.99\%) & & 2589 (3.05\%) & $82,211(96.95 \%)$ & \\
\hline Mean Age & 43.5 & 42.1 & $<0.001$ & 42.3028 & 42.09298 & 0.462 \\
\hline Gender \% & & & $<0.001$ & & & 0.004 \\
\hline Male & 56.69 & 61.26 & & 64.39 & 61.16 & \\
\hline Female & 29.93 & 37.29 & & 34.26 & 37.38 & \\
\hline Other/Unknown & 13.38 & 1.46 & & 1.35 & 1.46 & \\
\hline Exposure \% & & & $<0.001$ & & & $<0.001$ \\
\hline PWID & 8.72 & 24.88 & & 27.54 & 24.79 & \\
\hline Non-PWID & 1.59 & 5.62 & & 4.56 & 5.65 & \\
\hline Unknown & 89.69 & 69.51 & & 67.9 & 69.56 & \\
\hline Year \% & & & $<0.001$ & & & $<0.001$ \\
\hline 2002 & 13.62 & 8.17 & & 9.08 & 8.14 & \\
\hline 2003 & 7.92 & 7.83 & & 8.88 & 7.8 & \\
\hline 2004 & 7.32 & 9.32 & & 16.92 & 9.08 & \\
\hline 2005 & 6.04 & 7.56 & & 14.99 & 7.33 & \\
\hline 2006 & 7.52 & 7.95 & & 7.69 & 7.96 & \\
\hline 2007 & 9.95 & 9.04 & & 7.26 & 9.09 & \\
\hline 2008 & 9.13 & 8.71 & & 7.38 & 8.75 & \\
\hline 2009 & 9.81 & 7.99 & & 5.45 & 8.07 & \\
\hline 2010 & 8.5 & 7.73 & & 4.98 & 7.82 & \\
\hline 2011 & 8.22 & 8.48 & & 6.26 & 8.55 & \\
\hline 2012 & 6.96 & 8.84 & & 5.79 & 8.93 & \\
\hline 2013 & 5.01 & 8.38 & & 5.33 & 8.47 & \\
\hline
\end{tabular}

All $p$-values are the result of chi-squared tests with the exception of Mean age which is a result of a two sample t-test

There are several limitations in the current study. First, HCV surveillance systems may not capture all HCV cases. While MDPH's MAVEN surveillance and electronic laboratory reporting system has led to improved efficiency and timeliness in capturing $\mathrm{HCV}$ data [19], disease surveillance data only include information on individuals who have been tested and reported to health authorities. People who are not tested or are not engaged in care are not represented in these data. Race/ethnicity data are missing or incomplete for many $\mathrm{HCV}$ cases, making it difficult to discern representation in the $\mathrm{HCV}$ surveillance data by race/ethnicity. Second, the MAVEN system captures address at time of report, typically many years after initial HCV infection, and residence rather than place of infection. As a result, spatial results may represent risk for $\mathrm{HCV}$ transmission 10-20 years earlier. However, in the absence of large cohort studies that follow PWID over time, starting at a young age and allowing for calculation of $\mathrm{HCV}$ incidence rates and a better understanding of the geographic location where transmission occurred, such case reporting systems offer the best option currently available on a statewide level. Third, our dataset includes people who are positive for anti-HCV antibody through EIA. It is possible that some $\mathrm{HCV}$ cases tested positive for antibody but negative for $\mathrm{HCV}$ ribonucleic acid, which would over-estimate $\mathrm{HCV}$ cases of prevalent infection. Spontaneous viral clearance occurs in approximately $25 \%$ of people initially diagnosed with HCV [34]. However, it is unlikely that there are differential spatial distributions for reported $\mathrm{HCV}$ cases that ultimately clear the virus compared to cases that do not. Fourth, in our statistical models, we assessed associations at the census tract level, rather than the individual level. HCV surveillance (outcomes) and ACS data (explanatory variables) for the entire state are included in our analyses, and represent the best data available on the micro (i.e., neighborhood) level, and have been used in previous small area analyses with similar outcomes [35]. Finally, differences in characteristics of $\mathrm{HCV}$ cases with and without addresses 
Table 3 Descriptive statistics of Massachusetts census tracts, 2002-2013 ( $n=1464)$

\begin{tabular}{|c|c|c|}
\hline Characteristic & $\begin{array}{l}\text { Census tracts in HCV hotspot }(n=302) \\
\text { Mean }(95 \% \mathrm{Cl})\end{array}$ & $\begin{array}{l}\text { Census tracts outside HCV hotspot }(n=1162) \\
\text { Mean }(95 \% \mathrm{Cl})\end{array}$ \\
\hline \multicolumn{3}{|l|}{ Demographic Variables } \\
\hline Male ${ }^{a}, \%$ & $48.32(47.99,48.48)$ & $48.23(47.99,48.48)$ \\
\hline Total population, no. per census tract & $3837(3663,4010)$ & $4577(4481,4673)$ \\
\hline Median age, years & $34.94(34.20,35.68)$ & $39.71(39.32,40.09)$ \\
\hline High School graduate or higher ${ }^{b}, \%$ & $81.59(80.03,83.15)$ & $89.18(88.61,89.75)$ \\
\hline White ${ }^{a, c}, \%$ & $70.57(68.14,73.00)$ & $82.99(81.83,84.14)$ \\
\hline African American ${ }^{a, c}, \%$ & $10.44(8.88,11.99)$ & $6.25(5.49,7.01)$ \\
\hline Hispanic $^{a, d}, \%$ & $16.80(14.74,18.86)$ & $8.33(7.50,9.16)$ \\
\hline Asian ${ }^{a, c}, \%$ & $7.60(6.51,8.69)$ & $4.49(4.14,4.84)$ \\
\hline Other Race or Ethnicity ${ }^{\mathrm{a}, \mathrm{e}}, \%$ & $7.56(6.43,8.69)$ & $4.35(3.79,4.91)$ \\
\hline \multicolumn{3}{|l|}{ Socioeconomic Variables } \\
\hline Median household income, $\$$ & $53,066(50,543,55,590)$ & $71,725(70,006,73,444)$ \\
\hline Households receiving food stamps ${ }^{a, g}, \%$, & $13.86(12.36,15.37)$ & $8.07(7.48,8.66)$ \\
\hline Households living at poverty status ${ }^{a, 9},(\%)$ & $10.16(9.17,11.15)$ & $12.40(11.73,13.08)$ \\
\hline Households with 1 worker ${ }^{a,}$, $(\%)$ & $27.85(26.95,28.75)$ & $29.26(28.71,29.80)$ \\
\hline Households with $\geq 2$ workers ${ }^{\mathrm{a}, \mathrm{g}}$, (\%) & $59.53(58.22,60.83)$ & $58.07(57.33,58.82)$ \\
\hline Owner-occupied housing units, \% & $42.78(40.22,45.34)$ & $67.46(66.10,68.82)$ \\
\hline Renter-occupied housing units, \% & $57.22(54.66,59.78)$ & $32.54(31.18,33.90)$ \\
\hline \multicolumn{3}{|l|}{ Structural Variables } \\
\hline Pharmacies, no. & $1.14(0.93,1.35)$ & $1.50(1.38,1.62)$ \\
\hline Gay bars, no. & $0.04(0.02,0.07)$ & $0.02(0.00,0.05)$ \\
\hline Adult bookstores, no. & $0.02(0.01,0.04)$ & $0.02(0.01,0.03)$ \\
\hline Syringe exchanges, no. & $0.007(0.00,0.02)$ & $0.00(0.00,0.00)$ \\
\hline HIV testing sites, no. & $0.36(0.22,0.49)$ & $0.10(0.07,0.14)$ \\
\hline Prisons, no. & $0.02(0.00,0.03)$ & $0.03(0.02,0.05)$ \\
\hline HCV cases $^{f}$, no. & $72.31(65.87,78.74)$ & $51.96(49.33,54.90)$ \\
\hline HCV rate per 100,000 individuals $^{f}$, no. & $2424(1544,3303)$ & $1220(1154,1286)$ \\
\hline
\end{tabular}

$n$ sample size, \% percent, \$ United States dollar, HCV hepatitis C virus, HIV human immunodeficiency virus, $C l$ confidence interval, IQR interquartile range

${ }^{\text {aPercent }}$ of total population within census tract

${ }^{\mathrm{b}}$ Population 25 years of age or older

'Non-Hispanic

${ }^{\mathrm{d}}$ Of any race

Includes Native Hawaiian/Pacific Islander, American Indian/Alaskan Native, and other races/ethnicities not specified

fReported HCV cases to the Massachusetts Department of Public Health from 2002 to 2013

'Last 12 months

and for matched and unmatched addresses following geocoding can help to illustrate which groups and characteristics may be underrepresented and can inform training needs for completion of future $\mathrm{HCV}$ case report forms, which can further enhance the precision of HCV surveillance data as well as spatial and statistical analyses.

\section{Future research}

There are a number of unique spatial analytical tools and approaches that are available to explore $\mathrm{HCV}$, and other infection clustering patterns, in MA and the US. Limited spatial epidemiological and geostatistical analysis of surveillance data has been performed to date, and the spatial uncertainty of such analyses is unknown. Future research should incorporate spatiotemporal cluster analyses, additional spatial modeling approaches, including Bayesian spatial and geostatistical models, and spatially weighted regression analyses, to enhance spatial precision and build upon our approaches. In addition, nuanced analyses that compare clustering patterns across different population subgroups and the role of the built environment are needed to determine differences by age cohort, risk behaviors, environment, and race/ethnicity over time. 
Table 4 Factors associated with HCV hotspots in Massachusetts, 2002-2013

\begin{tabular}{|c|c|c|c|}
\hline Characteristic & & Unadjusted model OR (95\% Cl) & Adjusted model ${ }^{\dagger}$ AOR $(95 \% \mathrm{Cl})$ \\
\hline \multirow[t]{2}{*}{$\overline{\text { Male }^{a}}$} & $<48.25 \%$ & Referent & \\
\hline & $\geq 48.25 \%$ & $0.88(0.68,1.14)$ & - \\
\hline \multirow[t]{2}{*}{ Female $^{a}$} & $<51.75 \%$ & Referent & \\
\hline & $\geq 51.75 \%$ & $1.13(0.88,1.46)$ & - \\
\hline \multirow[t]{2}{*}{ Total population, No. per census tract } & $<4248$ & Referent & Referent \\
\hline & $\geq 4248$ & $0.50(0.38,0.64)$ & $1.08(0.80,1.47)$ \\
\hline Median age, years & & $0.90(0.89,0.92)$ & $1.02(0.99,1.06)$ \\
\hline High School graduate or higher ${ }^{\mathrm{b}}, \%$ & & $0.95(0.94,0.96)$ & $0.91(0.89,0.93)$ \\
\hline White ${ }^{a, c}, \%$ & & $0.98(0.97,0.98)$ & - \\
\hline African American ${ }^{\mathrm{a}, \mathrm{c}}, \%$ & & $1.02(1.01,1.03)$ & $1.01(1.00,1.02)$ \\
\hline Hispanic ${ }^{a, d}, \%$ & & $1.03(1.02,1.04)$ & $1.07(1.04,1.09)$ \\
\hline Asian $^{a, c}, \%$ & & $1.05(1.04,1.07)$ & - \\
\hline Other Race or Ethnicity ${ }^{a}$,,$\%$ & & $1.03(1.02,1.04)$ & $0.88(0.85,0.91)$ \\
\hline \multirow[t]{2}{*}{ Median annual household income, $\$$} & $<\$ 65,571$ & Referent & Referent \\
\hline & $\geq \$ 65,571$ & $0.32(0.24,0.42)$ & $0.91(0.60,1.39)$ \\
\hline \multirow[t]{2}{*}{ Households receiving food stamps, $\%$} & $<4.85 \%$ & Referent & Referent \\
\hline & $\geq 4.85 \%$ & $3.01(2.29,3.95)$ & $1.83(1.22,2.74)$ \\
\hline \multirow[t]{3}{*}{ Households living in poverty ${ }^{f}$} & $<5.6 \%$ & Referent & Referent \\
\hline & $\geq 5.6 \%$ to $<11.8 \%$ & $1.01(0.73,1.37)$ & $1.19(0.81,1.73)$ \\
\hline & $\geq 11.8 \%$ & $0.73(0.53,1.00)$ & $1.38(0.91,2.08)$ \\
\hline \multirow[t]{3}{*}{ Households with one worker $^{f}$} & $<24.6 \%$ & Referent & Referent \\
\hline & $\geq 24.6 \%$ to $<31.0 \%$ & $0.77(0.56,1.04)$ & $1.28(0.84,1.95)$ \\
\hline & $\geq 31.0 \%$ & $0.71(0.51,0.97)$ & $1.37(0.79,2.36)$ \\
\hline \multirow[t]{3}{*}{ Households with two or more workers ${ }^{f}$} & $<55.6 \%$ & Referent & Referent \\
\hline & $\geq 55.6 \%$ to $<64.7 \%$ & $1.01(0.73,1.39)$ & $0.80(0.51,1.27)$ \\
\hline & $\geq 64.7 \%$ & $1.27(0.94,1.73)$ & $1.06(0.60,1.90)$ \\
\hline Renter-occupied housing units, \% & & $1.04(1.03,1.05)$ & $1.00(0.99,1.01)$ \\
\hline Pharmacies, no. & & $0.91(0.85,0.97)$ & $0.96(0.90,1.04)$ \\
\hline Gay bars, no. & & $1.07(0.85,1.35)$ & - \\
\hline Adult bookstores, no. & & $1.06(0.50,2.26)$ & - \\
\hline Syringe exchanges, no. & & $3.87(0.54,27.56)$ & $1.61(0.18,14.59)$ \\
\hline HIV testing sites, no. & & $1.37(1.19,1.57)$ & $0.97(0.81,1.160)$ \\
\hline Prisons, no. & & $0.67(0.31,1.44)$ & - \\
\hline
\end{tabular}

$n$ sample size, \% percent, \$ United States dollar, HCV hepatitis $C$ virus, HIV human immunodeficiency virus, $S D$ standard deviation, IQR interquartile range, OR odds ratio, $A O R$ adjusted odds ratio, $\mathrm{Cl}$ confidence interval. Italicized text represents statistically significant results $(p<0.05)$

${ }^{\dagger}$ Adjusted for: number of pharmacies, number of syringe exchanges, number of HIV testing sites, percent of the total population that was a high school graduate or higher, total population, median household income, percent of renter-occupied housing units, percent of households received food stamps, percent of total population that was Hispanic, percent of total population that was African American, percent of total population that was another race/ethnicity, percent of households living at poverty status, percent of households with one worker, and percent of households with two or more workers

${ }^{\text {aPercent }}$ of total population within census tract

bopulation 25 years of age or older

'Non-Hispanic

${ }^{\mathrm{d}}$ Of any race

eIncludes Native Hawaiian/Pacific Islander, American Indian/Alaskan Native, and other races/ethnicities not specified

fLast 12 months

\section{Conclusions}

Combined geospatial and statistical analyses can help identify regions of risk and regions of disease, and inform public health policy decisions. Through our analytical approach, we identified and characterized clusters in MA where enhanced HCV screening, prevention, treatment, and care could help to combat the $\mathrm{HCV}$ epidemic. 


\section{Abbreviations}

ACS: American Community Survey; AOR: Adjusted Odds Ratio; CDC: Centers for Disease Control and Prevention; Cl: Confidence Interval; ElA: Enzyme Immunoassay; GIS: Geographic Information System; HCV: Hepatitis C Virus; HIV: Human Immunodeficiency Virus; KDE: Kernel Density Estimates; MA: Massachusetts; MAVEN: Massachusetts Virtual Epidemiologic Network; MDPH: Massachusetts Department of Public Health; PWID: People who Inject Drugs; TIGER: Topologically Integrated Geographic Encoding and Referencing

\section{Acknowledgements}

We are grateful to Dr. Monina Klevens, Dr. Al DeMaria, and Mr. Kevin Cranston for their invaluable review of an earlier version of this manuscript.

\section{Funding}

This research was funded in part by a 2014 developmental and 2015 supplemental grant from the Providence/Boston Center for AIDS Research (PI: Stopka). The project described was supported by Grant Number P30AI042853 from the National Institute of Allergy and Infectious Diseases. The content is solely the responsibility of the authors and does not necessarily represent the official views of the National Institute of Allergy and Infectious Diseases or the National Institute of Health.

\section{Availability of data and materials}

The data that support the findings of this study are available from the Massachusetts Department of Public Health but restrictions apply to the availability of these data, which were used under agreement and IRB approval for the current study, and so are not publicly available. Data may be available from the Massachusetts Department of Public Health: DPH.IRB@state.ma.us.

\section{Authors' contributions}

TS conceptualized the study, oversaw study implementation and all GIS and spatial analyses, and interpreted findings. MG developed statistical models and interpreted the analytical results regarding factors associated with HCV hotpots. DM conducted GIS and spatial analyses and interpreted HCV hotspots results. $\mathrm{MH}$ contributed to GIS mapping and spatial analyses, and assisted in interpreting HCV hotspots results. KB configured the MDPH HCV surveillance dataset, facilitated access to data, and assisted with variable definitions and interpretation of findings. SO provided guidance on the HCV surveillance data and informed analytical approaches and interpretation of findings. DC oversaw HCV surveillance data access and informed analytical approaches and interpretation of findings. AD assisted with GIS mapping and spatial analysis of HCV surveillance data. KC oversaw all statistical modeling and analyses and contributed to interpretation of results. All authors read and approved the final manuscript.

\section{Competing interests}

The authors declare that they have no competing interests.

\section{Consent for publication}

Not applicable.

\section{Ethics approval and consent to participate}

This study was reviewed and approved by the Tufts University Health Sciences and Massachusetts Department of Public Health Institutional Review Boards.

\section{Publisher's Note}

Springer Nature remains neutral with regard to jurisdictional claims in published maps and institutional affiliations.

\section{Author details}

${ }^{1}$ Department of Public Health and Community Medicine, Tufts University School of Medicine, 136 Harrison Avenue, Boston, MA 02111, USA. 2 Department of Health Policy and Management, Harvard T. H. Chan School of Public Health, 677 Huntington Ave, Boston, MA 02115, USA. ${ }^{3}$ Bureau of Infectious Disease and Laboratory Sciences, Massachusetts Department of Public Health, 350 South Street, Jamaica Plain, MA 02130, USA.
Received: 27 January 2017 Accepted: 11 April 2017

Published online: 20 April 2017

\section{References}

1. POLARIS. Global prevalence and genotype distribution of hepatitis $C$ virus infection in 2015: a modelling study. Lancet Gastro Hep. 2016;2(3):161-76.

2. Denniston MM, Jiles RB, Drobeniuc J, et al. Chronic hepatitis C virus infection in the United States, National Health and nutrition examination survey 2003 to 2010. Ann Intern Med. 2014;160(5):293-300.

3. Ly KN, Xing J, Klevens RM, Jiles RB, Ward JW, Holmberg SD. The increasing burden of mortality from viral hepatitis in the United States between 1999 and 2007. Ann Intern Med. 2012;156(4):271-8.

4. Suryaprasad $A G$, White $J Z, X u F$, et al. Emerging epidemic of hepatitis $C$ virus infections among young nonurban persons who inject drugs in the United States, 2006-2012. Clin Infect Dis. 2014;59(10):1411-9.

5. Williams I. Epidemiology of hepatitis C in the United States. Am J Med. 1999;107(6B):2S-9S.

6. Amon J, Garfein R, Ahdieh-Grant L, et al. Prevalence of hepatitis C virus infection among injection drug users in the United States, 1994-2004. Clin Infect Dis. 2008:46(12):1852-8.

7. Armstrong G, Wasley A, Simard E, McQuillan G, Kuhnert W, Alter M. The prevalence of hepatitis C virus infection in the United States, 1999 through 2002. Ann Intern Med. 2006;144(10):705-14.

8. Garfein RS, Doherty MC, Monterroso ER, Thomas DL, Nelson KE, Vlahov D. Prevalence and incidence of hepatitis C virus infection among young adult injection drug users. J Acquir Immune Defic Syndr Hum Retrovirol. 1998; 18(Suppl 1):S11-9.

9. Hepatitis C. Virus infection among adolescents and young adults: Massachusetts, 2002-2009. MMWR Morb Mortal Wkly Rep. 2011;60(17):537-41.

10. Bureau of Infectious Diseases, MDPH. Shifting epidemics: HIV and hepatitis C infection among injection drug users in Massachusetts. 2012.

11. Institute of Medicine (US). Committee on the Prevention and Control of Viral Hepatitis Infection. In: Colvin HM, Mitchell AE, editors. Washington (DC) National Academies Press (US); 2010.

12. Moonan PK, Oppong J, Sahbazian B, et al. What is the outcome of targeted tuberculosis screening based on universal genotyping and location? Am J Respir Crit Care Med. 2006:174(5):599-604.

13. Geanuracos CG, Cunningham SD, Weiss G, Forte D, Reid LM, Ellen JM. Use of geographic information systems for planning HIV prevention interventions for high-risk youths. Am J Public Health. 2007;97(11):1974-81.

14. Magnus M, Kuo I, Shelley K, et al. Risk factors driving the emergence of a generalized heterosexual HIV epidemic in Washington, District of Columbia networks at risk. AIDS. 2009;23(10):1277-84.

15. Goswami ND, Hecker EJ, Vickery C, et al. Geographic information systembased screening for TB, HIV, and syphilis (GIS-THIS): a cross-sectional study. PLoS One. 2012;7(10):e46029.

16. Morano JP, Gibson BA, Altice FL. The burgeoning HIV/HCV syndemic in the urban northeast: HCV, HIV, and HIV/HCV coinfection in an urban setting. PLoS One. 2013;8(5):e64321.

17. Brouwer KC, Rusch ML, Weeks JR, et al. Spatial epidemiology of HIV among injection drug users in Tijuana. Mexico Ann Assoc Am Geogr. 2012;102(5): 1190-9.

18. Meyers DJ, Hood ME, Stopka TJ. HIV and hepatitis C mortality in Massachusetts, 2002-2011: spatial cluster and trend analysis of HIV and HCV using multiple cause of death. PLoS One. 2014;9(12):e114822.

19. Heisey-Grove DM, Church DR, Haney GA, Demaria A. Enhancing surveillance for hepatitis C through public health informatics. Public Health Rep. 2011; 126(1):13-8

20. United States Census Bureau. American FactFinder. Available at: https:// factfinder.census.gov/faces/nav/jsf/pages/index.xhtml.

21. Drummond WJ. Address matching: GIS technology for mapping human activity patterns. J Am Plan Assoc. 1995;61(2):240-51.

22. Krieger N, Waterman P, Lemieux K, Zierler S, Hogan JW. On the wrong side of the tracts? Evaluating the accuracy of geocoding in public health research. Am J Public Health. 2001;91(7):1114-6.

23. Cooper HL, Bossak BH, Tempalski B, Friedman SR, Des Jarlais DC. Temporal trends in spatial access to pharmacies that sell over-the-counter syringes in new York City health districts: relationship to local racial/ethnic composition and need. J Urban Health. 2009;86(6):929-45.

24. Ord J, Getis A. Local spatial autocorrelation statistics: distributional issues and an application. Geogr Anal. 1995;27:286-306. 
25. Bailey SL, Ouellet LJ, Mackesy-Amiti ME, et al. Perceived risk, peer influences, and injection partner type predict receptive syringe sharing among young adult injection drug users in five U.S. cities. Drug Alcohol Depend. 2007; 91(Suppl 1):S18-29.

26. Kulldorff M, Heffernan R, Hartman J, Assunção R, Mostashari F. A space-time permutation scan statistic for disease outbreak detection. PLoS Med. 2005; 2(3):e59.

27. Stopka TJ, Krawczyk C, Gradziel P, Geraghty EM. Use of spatial epidemiology and hot spot analysis to target women eligible for prenatal women, infants, and children services. Am J Public Health. 2014;104(Suppl 1):S183-9.

28. Tohme RA, Xing J, Liao Y, Holmberg SD. Hepatitis C testing, infection, and linkage to care among racial and ethnic minorities in the United States, 2009-2010. Am J Public Health. 2013;103(1):112-9.

29. Grebely J, Robaeys G, Bruggmann P, et al. Recommendations for the management of hepatitis $C$ virus infection among people who inject drugs. Int J Drug Policy. 2015;26(10):1028-38.

30. Cousien A, Tran VC, Deuffic-Burban S, Jauffret-Roustide M, Dhersin JS, Yazdanpanah Y. Hepatitis $C$ treatment as prevention of viral transmission and liver-related morbidity in persons who inject drugs. Hepatology. 2016; 63(4):1090-101.

31. Martin NK, Vickerman P, Grebely J, et al. Hepatitis C virus treatment for prevention among people who inject drugs: modeling treatment scale-up in the age of direct-acting antivirals. Hepatology. 2013;58(5):1598-609.

32. Robaeys G, Grebely J, Mauss S, et al. Recommendations for the management of hepatitis $C$ virus infection among people who inject drugs. Clin Infect Dis. 2013:57(Suppl 2):S129-37.

33. Barua S, Greenwald R, Grebely J, Dore GJ, Swan T, Taylor LE. Restrictions for Medicaid reimbursement of Sofosbuvir for the treatment of hepatitis $C$ virus infection in the United States. Ann Intern Med. 2015;163(3):215-23.

34. Conrad C, Bradley HM, Broz D, et al. Community outbreak of HIV infection linked to injection drug use of Oxymorphone - Indiana, 2015. MMWR Morb Mortal Wkly Rep. 2015;64(16):443-4.

35. Krieger N, Chen JT, Waterman PD, Rehkopf DH, Subramanian SV. Race/ ethnicity, gender, and monitoring socioeconomic gradients in health: a comparison of area-based socioeconomic measures-the public health disparities geocoding project. Am J Public Health. 2003;93(10):1655-71.

\section{Submit your next manuscript to BioMed Central and we will help you at every step:}

- We accept pre-submission inquiries

- Our selector tool helps you to find the most relevant journal

- We provide round the clock customer support

- Convenient online submission

- Thorough peer review

- Inclusion in PubMed and all major indexing services

- Maximum visibility for your research

Submit your manuscript at www biomedcentral com/submit
() BioMed Central 